\title{
Relevância e ensino: reflexão sobre a noção apropriada de contexto nas situações de ensino e aprendizagem de língua portuguesa à luz de teorias pragmáticas da comunicação \\ Relevance and teaching: reflecting on the appropriate notion of context in Portuguese learning/teaching situations in light of communication pragmatic theories
}

\author{
Dóris Cristina Gedrat ${ }^{*}$
}

\begin{abstract}
RESUMO: Neste trabalho, mostra-se qual a noção apropriada de contexto durante a comunicação na sala de aula de português, possibilitando o máximo de ganhos cognitivos possível ao estudante. O contexto é considerado o conjunto de informações manifestáveis no momento da comunicação, dentro do qual as novas informações atingirão maior ou menor relevância para cada comunicador, segundo a teoria da relevância, de Sperber e Wilson (1986/1995). Essa noção representa um aprimoramento do contexto conforme definido anteriormente por Grice (1989), quando o conhecimento mútuo tinha papel central e não se considerava a compreensão que o ouvinte tinha e que não havia sido intencionada pelo falante. Por informação relevante entende-se a informação que, em contato com as informações e suposições já existentes no contexto, produz o máximo de efeitos contextuais pelo mínimo esforço de processamento mental possível. O processo de ensino-aprendizagem aqui é compreendido como um processo da mente, que o aprendiz desenvolve através da associação entre o seu conhecimento

ABSTRACT: This paper points out which is the adequate notion of communicative context in Portuguese language classroom in order for the teaching-learning process to be full of cognitive gains for students. Context here is taken as a set of manifestable information and assumptions during communication, in which new information will be less or more relevant for each one of the participants, following Sperber and Wilson's (1986/1995) relevance theory. This concept is an upgrading of earlier Grice's (1989) notion of context, in which mutual knowledge used to play an essential role in the context and the part of the hearer's comprehension which had not been intended by the speaker was never considered. Relevant information means the information that, when in contact with information and assumptions already present in the context, originate the maximum contextual effects possible for the minimum mental effort possible. Teachinglearning is understood as a mental process which the student develops by the association between his/her encyclopedic knowledge and the new information with which he gets in touch.
\end{abstract} enciclopédico e as novas informações com as quais entra em contato.

PALAVRAS-CHAVE: Contexto de comunicação. Relevância. Ensinoaprendizagem de língua portuguesa.

\footnotetext{
${ }^{*}$ Curso de Letras da Universidade Luterana do Brasil (ULBRA), campus Canoas.
} 


\section{Introdução}

Desde Aristóteles até a semiótica moderna, o modelo predominante para explicar a comunicação foi o modelo de código. Um código é um sistema que emparelha mensagens internas com sinais externos, possibilitando, assim, que dois organismos ou máquinas se comuniquem. Dentro dessas teorias, criaram-se metáforas como as sentenças carregam os pensamento e os pensamentos são empacotados e transferidos linguisticamente, as quais dão uma visão distorcida do fenômeno, não realmente descrevendo como ele se realiza. Como explicar a compreensão de mensagens através da mera decodificação de sinais?

Certamente, existe um código envolvido na comunicação humana, e as pessoas comunicam pensamentos. No entanto, o pensamento comunicado não se reduz àquilo que os sinais representam. Há uma lacuna entre a representação semântica das sentenças e os pensamentos realmente comunicados por enunciados. Essa lacuna é preenchida por intermédio de inferenciação, e não de mais codificação, segundo o modelo inferencial que Grice propôs na segunda metade do século XX.

Grice, em seu artigo Logic and Conversation, publicado em 1967 (GRICE, 1989, p.2240), propôs-se descrever, com o máximo de clareza possível, as regras ou princípios que entram no cálculo para a compreensão do significado e que governam não apenas o comportamento linguístico, mas também o não linguístico. Com o avanço da ciência, novas formulações foram surgindo, causando acréscimos e refutações, tentando precisar ao máximo as propriedades pragmáticas do significado.

Sperber e Wilson, nos anos 80, construíram uma teoria da comunicação que partiu de Grice, mas tomou outros rumos na tentativa de responder perguntas cujas respostas não encontraram em Grice. Perguntas como, por exemplo: qual a natureza do princípio de cooperação e as máximas? são universais? são inatas? é necessário que haja cooperação para haver comunicação? os falantes realmente têm por objetivo a veracidade, a informatividade, a relevância e a clareza? o que é relevância exatamente? (SMITH e WILSON,1992, p.1-10).

Mas a diferença entre a teoria de Grice e a de Sperber e Wilson que mais interessa aqui é o fato de que o papel do contexto na comunicação não foi claramente definido por Grice (1989), em Logic and Conversation. Sperber e Wilson mostram que o contexto para a interpretação de enunciados geralmente não é fixado antecipadamente, mas construído juntamente com o processo de interpretação. Os autores tomam esse fato como mais uma indicação de que a interpretação de um enunciado foge aos limites daquilo que é codificado linguisticamente. Para eles, a construção 
do contexto é governada pelos mesmos princípios pragmáticos que afetam o resgate do conteúdo explícito e das implicaturas.

Defende-se, neste texto, que a noção de contexto da teoria da relevância é a mais adequada para o ensino-aprendizagem de língua portuguesa. Para aprender, é importante que o estudante participe da construção do contexto durante a comunicação em sala de aula. Retomase o modelo inferencial de Grice, que explicou a formação do contexto e a compreensão durante a comunicação baseando-se nas intenções dos falantes/ouvintes, para, em seguida, destacaremse os pontos nos quais essa teoria não dá conta de como os seres humanos comunicam seus pensamentos e como o contexto vai se formando e transformando durante a comunicação, conforme Sperber e Wilson, na teoria da relevância. Finalmente, indica-se de que forma o contexto segundo a teoria da relevância é adequado para as situações de ensino-aprendizagem de língua portuguesa. Isso é feito mediante o resgate de conclusões de linguistas que identificaram as principais falhas no ensino-aprendizagem de língua portuguesa. Tais falhas parecem ser, em grande parte, fruto de um contexto construído com base em conceitos préconcebidos sobre a língua e sobre a compreensão durante a comunicação, um contexto que não considera a cognição humana e as características individuais dos alunos.

\section{Comunicação num contexto inferencial: a teoria da conversação de Grice}

Entre os vários projetos filosóficos de Grice está a teoria da conversação, exposta no texto de 1967 (Logic and Conversation), que parece estar fortemente conectada com os primeiros textos importantes, principalmente com sua teoria da significação natural e não natural (significado-nn) ${ }^{1}$. Nesta a ideia principal proposta por Grice é expressa em (1):

(1) Significado não natural, ou significado-nn, segundo Grice Ao enunciar $x, F$ significou-nn $p$ é equivalente a $F$ intencionou que o enunciado $x$ produzisse algum efeito em $R$ através do reconhecimento dessa intenção, por parte de $R$.

$\mathrm{F}=$ falante/emissor

$\mathrm{X}=$ enunciado produzido por $\mathrm{F}$

$\mathrm{R}=$ ouvinte/receptor ${ }^{2}$

\footnotetext{
${ }^{1}$ Meaning (Grice, 1989, p213-223), de 1957.

${ }^{2}$ Falante e Emissor aqui têm o mesmo significado, assim como Ouvinte e Receptor.
} 
Em outras palavras, não há significado-nn por acaso, sem uma intenção do falante. Nessa primeira tentativa de dizer o que é o significado, Grice deixa claro que deve ser possível explicar o significado de uma expressão em termos daquilo que os usuários da língua querem dizer, ou significam-nn, com a expressão numa determinada ocasião. Quanto ao que o falante diz, ele explica, vagamente (GRICE, 1989, p.25), que está intimamente relacionado ao significado convencional das palavras ou sentenças enunciadas, o que leva a crer que o que é dito é a parte do significado verificável sob condições de verdade, mas não corresponde ao significado comunicado.

Em alguns casos, o significado convencional das sentenças, segundo Grice, nao é determinado apenas pelo que é dito, mas também pelo convencionalmente implicado, como demonstra o exemplo em (2):

(2) O Banrisul é gaúcho, portanto é confiável.

Em (2), o falante não disse que o fato de o Banrisul ser confiável segue-se do fato de ele ser gaúcho, pois, mesmo que essa relação de consequência não se sustentasse, o enunciado de (2) não seria falso. Contudo, ao enunciar (2), o falante indicou, ou implicou convencionalmente, que ser confiável é consequência de ser gaúcho, devido ao conetivo portanto. Grice chama essa implicatura de convencional porque em qualquer contexto essa relação será estabelecida entre duas orações ligadas pelo conetivo, e, ao mesmo tempo, essa relação não afeta as condições de verdade da sentença.

As sentenças (3) e (4) têm as mesmas condições de verdade que as de (2):

(3) O Banrisul é gaúcho e é confiável.

(4) O Banrisul é gaúcho mas é confiável.

Em outras palavras, se os dois conjuntos forem verdadeiros, a sentença será verdadeira. Portanto, para Grice, o significado convencional da linguagem é o dito mais o convencionalmente implicado, o que, segundo ele, os participantes identificam por sua própria intuição.

A parte do significado não convencional divide-se em conversacionalmente implicada e não conversacionalmente implicada. A significação não conversacionalmente implicada o é, segundo Grice (1989, p.28), a partir de máximas estéticas, sociais ou morais, o que ele não desenvolveu e, da mesma forma, não será destacado aqui. O significado implicado 
conversacionalmente Grice denominou implicaturas conversacionais, as quais ele explica através da sua teoria da comunicação.

Segundo Grice, ao comunicarem-se, as pessoas são orientadas, sem consciência disso, por princípios e regras da conversação. Tais regras levam-nas a dialogar da forma mais cooperativa possível, visando ao maior grau de univocidade atingível na troca de informações. Daí vem a denominação Princípio de Cooperação. Esse princípio compõe-se de máximas e submáximas, arranjadas em categorias, conforme exposto em (5):

(5) O Princípio de Cooperação de Grice

Faça sua contribuição conversacional conforme exigido, no estágio em que se encontra a conversação, de acordo com o propósito ou direção da mesma.

1. Categoria da Qualidade: procure afirmar coisas verdadeiras.

(i) Não afirme o que você acredita ser falso. adequada.

(ii) Não afirme algo para o qual você não possa fornecer evidência

2. Categoria da Quantidade:

(i) Faça com que sua mensagem seja tão informativa quanto necessária conforme os propósitos da conversação.

(ii) Não dê mais informações do que o necessário.

3. Categoria da Relação: seja relevante.

4. Categoria da Maneira: seja claro.

(i) Evite obscuridade de expressão.

(ii) Evite ambiguidade.

(iii) Seja breve.

(iv) Seja ordenado.

Uma implicatura conversacional pode ser produzida mediante a observação ou a quebra de uma máxima. Observe-se o diálogo em (6):

(6) A: Estou farta desta dor de cabeça.

B: Tome panadol.

A resposta de B sugere que ele coopera com A, na medida em que ele possui evidências de que panadol é um remédio que cura dores de cabeça, ou seja, está obedecendo à máxima da qualidade, mesmo que, aparentemente, possa estar violando a máxima da relação, mudando o tópico do assunto. Ao dizer que A deve tomar panadol, B implica conversacionalmente que panadol é bom contra dores de cabeça. Trata-se de uma implicatura por observação das máximas.

Considere-se (7): 
(7) Neymar fez dois gols.

Seria compatível com as condições de verdade de (7) que Neymar tivesse feito mais do que dois gols, pois dois não acarreta apenas dois. Se Neymar fez apenas dois gols é falso, Neymar fez dois gols não é necessariamente falso, logo, aquela não é consequência lógica desta. Porém, pela máxima da quantidade, deve-se dar toda a informação exigida, então, caso Neymar tivesse feito mais do que dois gols, o falante o teria dito. Do contrário, não estaria sendo cooperativo. Em outras palavras, (7) implica, pela obediência à máxima da quantidade, que Neymar fez apenas dois gols. O efeito desta máxima é acrescentar ao enunciado uma inferência pragmática que diga que a afirmação utilizada é a mais forte ou informativa para aquela situação. (LEVINSON,1983, p.106).

Por outro lado, considere-se (8):

(8) A: Você gosta de chinelos Samoa?

B: O chinelo Samoa é para quem tem o que fazer.

O falante B está violando o princípio de cooperação, pois quebra a máxima da quantidade, ao dar mais informação do que o solicitado, e a máxima da relevância, ao responder algo não diretamente relacionado à pergunta de $\mathrm{A}$. Mas, ao reconhecer que B está desobedecendo ao princípio, A, ao mesmo tempo, supõe que B esteja querendo comunicar algo através dessa quebra. Como afirma Grice, os participantes de uma conversação nunca dizem as coisas só por dizer, mas sempre com um propósito ${ }^{3}$. Após realizar um cálculo mental e inconsciente, processado em frações de segundos, A inferirá, do enunciado de B, que os outros chinelos são para pessoas desocupadas, preguiçosas, que não têm nada para fazer, sem objetivos, etc. $\mathrm{O}$ fato de $\mathrm{B}$ violar uma ou mais máximas não quer dizer que ele não esteja cooperando, e sim que ele está cooperando num nível mais profundo, de forma que A deverá realizar um cálculo de inferência mais extenso para concluir outras proposições. Ao realizar esse cálculo, A está procurando encaixar o que B disse dentro do princípio de cooperação. O que A inferiu é o que B implicou conversacionalmente, por quebra ou exploração de máximas, segundo Grice.

\footnotetext{
${ }^{3}$ Ou, segundo Sperber \& Wilson (1986/1995), os enunciados já vêm com uma presunção de relevância garantida. Nunca se diz algo irrelevante para os propósitos comunicativos dos participantes no discurso, este é, segundo os autores, um princípio da cognição humana que dirige a comunicação.
} 
Todas as implicaturas até agora apresentadas são o que Grice chamou de implicaturas particularizadas, aquelas que dependem de informações do contexto para que possam ser calculadas. Por exemplo, para que o ouvinte infira com precisão a implicatura de B, em (8) acima, as seguintes informações devem estar presentes no contexto particular da conversação: Existem tipos de chinelos para pessoas que não têm o que fazer e existem tipos de chinelos para pessoas que têm o que fazer; O Rider é um chinelo cuja propaganda destaca o uso do mesmo por pessoas em férias, tranquilas, sem compromisso; O Samoa, como resposta, dá importância, exatamente, ao fato de seus usuários terem o que fazer na vida, emprestando uma conatação positiva ao que a propaganda do Rider deixava entender como indesejado; As pessoas, normalmente, preferem identificar-se com um tipo ativo, ou seja, que tem o que fazer, logo, por isso gostam de Samoa e não de Rider.

Grice (1989, p. 37) também distinguiu as implicaturas conversacionais generalizadas, em oposição às particularizadas. Ao contrário destas, aquelas não exigem um contexto especial ou cenário para surgirem. O exemplo que Grice (1989, p. 37) mesmo dá é quanto ao uso de sentenças como (9):

(9) Entrei numa casa.

Sempre que alguém disser (9) não estará se referindo à sua própria casa, caso contrário não estaria cooperando por não dizê-lo. Grice (1989, p. 37) mesmo admite que esse tipo de implicatura conversacional pode levantar confusão por parecer-se muito com as implicaturas convencionais.

Segundo a teoria de Grice (1898, p.30), uma implicatura conversacional pode ser definida como em (10):

(10) A Implicatura Conversacional de Grice

F diz que $\mathrm{p}$ implica conversacionalmente que $\mathrm{q}$ se, e somente se:

(i) presume-se que F esteja observando as máximas, ou pelo menos (no caso de violações) o princípio cooperativo;

(ii) para manter tal suposição, deve-se supor que $\mathrm{F}$ pense que q;

(iii) $\mathrm{F}$ pensa que tanto $\mathrm{F}$ como o receptor $\mathrm{R}$ sabem mutuamente que $\mathrm{R}$ é capaz de calcular que, para preservar a suposição em (i), q é necessário.

Para que R possa calcular a implicatura q, segundo Grice (1989, p.31), ele deve saber, ou acreditar que sabe as informações em (11): 
(11) Conhecimento necessário para o cálculo das implicaturas

i. o conteúdo convencional da sentença enunciada;

ii. o princípio de cooperação e suas máximas;

iii. o contexto da sentença enunciada;

iv. algumas informações do cenário (por exemplo, que a sentença é abertamente falsa);

v. que i-iv são conhecimento mútuo partilhado pelo falante e o ouvinte.

Grice (1989, p. 31) mostra o cálculo padrão a ser realizado pelo ouvinte para derivar uma implicatura:

(12) Cálculo para a derivação de implicaturas conversacionais

i. F disse que p;

ii. não há razão para se pensar que F não esteja observando as máximas ou, pelo menos, o princípio cooperativo;

iii. para que $\mathrm{F}$ diga que $\mathrm{p}$ e, de fato, esteja observando as máximas ou o princípio cooperativo, $\mathrm{F}$ deve pensar que q;

iv. F deve saber que é de conhecimento mútuo que q deve ser suposto se for suposto que F está cooperando;

v. $\quad F$ nada fez para impedir que $\mathrm{R}$ pense que $\mathrm{q}$;

vi. portanto, $\mathrm{F}$ pretende que $\mathrm{R}$ pense que $\mathrm{q}$ e, ao dizer que $\mathrm{p}$, implicou $\mathrm{q}$.

O cálculo descrito por Grice, em (12), para a derivação de implicaturas conversacionais, transmite uma forte impressão de que o contexto durante o ato de comunicação é um contexto um tanto quanto determinado e determinável, não incluindo a possibilidade de os participantes derivarem inferências não previstas no princípio de cooperação. Também não se menciona que as pessoas possam derivar diferentes significados implicados umas das outras, o que, na realidade, ocorre naturalmente. Por exemplo, com referência ao enunciado analisado em (8), é possível considerar uma interpretação em que o falante B não considere os chinelos Samoa os melhores, pois ele está aposentado e completamente empenhado em descansar e usufruir de seu lazer, não tendo o que fazer conforme a noção corriqueira desse conceito, ligada a trabalho e compromissos. Nesse caso, a implicatura derivada pelo falante A seria totalmente diferente daquela apontada acima, mas, para que isso seja demonstrado, é necessário que o contexto seja dinâmico e inclua muito mais informações do que o faz o contexto descrito por Grice.

Os exemplos vistos são de contextos de situações possíveis em conversações de modo geral, mas, quando se fala em ensino-aprendizagem, também se deve considerar o contexto da comunicação, uma vez que se ensina através do diálogo, da conversa, predominantemente. No caso dessas situações, no entanto, não serão analisadas conversas propriamente ditas, mas como a 
comunicação entre professor e alunos acontece ao longo dos encontros e como a informação continua sendo processada e os efeitos contextuais sendo originados a partir do que se propõe aos alunos. Em outras palavras, não se trata de conversações do tipo exemplificado ao se apresentar as teorias, mas das propostas feitas para se ensinar e aprender e da condução da comunicação em situações de ensino-aprendizagem.

Considerando o cálculo de Grice para as implicaturas, em (12), pode-se ver que esse cálculo é baseado em conhecimento mútuo pressuposto, não na associação entre a informação nova e o conhecimento enciclopédico armazenado na mente do ouvinte, conforme a teoria da relevância, apresentada na próxima seção. O docente que supõe o que o estudante sabe para, então, propor o conteúdo a ser estudado estará criando um contexto não dinâmico, se comparado a outro que possibilite ao estudante as mais diversas associações entre o novo conteúdo e os conceitos e suposições presentes em seu ambiente cognitivo.

Em geral, os cientistas preocupados em explicar como a linguagem humana é utilizada para se dizerem coisas e como aqueles que ouvem entendem o que foi dito, concordam que a maior contribuição dada por Grice foi a descoberta de que aquilo que se diz ou escreve, o dito de Grice, de forma alguma representa toda a mensagem transmitida pelo enunciado. Para que o ouvinte realmente compreenda o que foi enunciado, ele terá de levar em conta as intenções de quem enunciou. Quando não consegue relacionar as intenções convencionalmente ligadas ao uso das expressões ao que o falante diz, automaticamente, realiza cálculos mentais segundo a suposição de que existem princípios convencionais que orientam a conversação, que o falante conhece tais princípios e não teria motivos para violar os mesmos e que, se o fez, foi com o propósito de comunicar algo através dessa violação.

Pela análise detida e detalhada da teoria de Grice e dos fenômenos linguísticos envolvidos no ato da comunicação, obras como Sperber e Wilson (1995), Wilson e Sperber (1991) e Carston (1988) observaram, em linhas gerais, que: (i) existe mais um nível de significado além do dito e do implicado e o dito não é determinado pelas condições de verdade apenas; (ii) pode-se subsumir todo o princípio de cooperação, juntamente com as máximas, num único princípio, o da relevância.

Grice descreveu como o ouvinte chega a inferir o que o falante pretendeu comunicar, mas ele não explica como e nem por que o ouvinte descarta outras possíveis conclusões quanto à intenção do falante. Em outras palavras, Grice mostra como ocorre a confirmação de hipóteses, 
mas não explica a formação das mesmas, não explicando, assim, a formação do contexto da comunicação. Sperber e Wilson (1986/1995), por outro lado, demonstram como interpretamos os enunciados a partir de premissas cujo conjunto é conhecido como o contexto. Conforme esses autores, o contexto é um construto psicológico, um subconjunto das suposições do ouvinte sobre o mundo. São essas informações e suposições que afetam a interpretação dos enunciados, e não o estado real do mundo. ${ }^{4}$

No que tange ao contexto de ensino-aprendizagem, também é necessário que se leve em conta as informações e suposições armazenadas na mente do estudante, para a interpretação da informação e, portanto, para a construção do conhecimento. Por exemplo, o estudante para o qual se apresenta a gramática como sendo a única variedade culta e aceitável da língua, conforme preconizado na Gramática Tradicional, não terá como desenvolver sua compreensão através da associação do que já sabe e do que está vendo. O contexto de suposições armazenadas em sua mente provém de sua experiência, que inclui diversas variedades da língua, tanto na escrita, quanto na fala, tanto com pessoas cultas, quanto com pessoas de nível escolar menos privilegiado, mas nada disso é suposto quando ele é conduzido a decorar as regras que regem a escrita formal, considerada a própria gramática. $\mathrm{O}$ conhecimento da língua que ele já tem não é considerado, impedindo-se, dessa forma, que ele aprenda mais a partir desse conhecimento.

O objetivo de Sperber e Wilson é identificar mecanismos subjacentes, enraizados na psicologia humana, os quais explicam como os humanos se comunicam uns com os outros. Eles se preocupam em definir de que maneira as pessoas formulam possibilidades de interpretação para enunciados e que elementos do contexto levam em conta para rejeitar uma possibilidade em detrimento de outra.

Na próxima seção, apresenta-se a abordagem que Sperber e Wilson propõem para a comunicação, enfatizando que o contexto não se constrói antes do ato comunicativo, nem é fixo durante a comunicação, mas vai se construindo e alterando à medida que a comunicação avança, podendo tomar formas diferentes na mente de diferentes interlocutores. Essa é a noção adequada de contexto de ensino-aprendizagem de língua portuguesa, em que o aluno participa da construção

\footnotetext{
${ }^{4}$ Utilizam-se, aqui os termos pensamento, informação e suposição conforme utilizados por Sperber e Wilson (1995, p. 2): “[...] com pensamentos queremos dizer representações conceituais (em oposição a representações sensoriais ou estados emocionais). Com suposições referimo-nos a pensamentos tratados pelo indivíduo como representações do mundo real (em oposição a ficções, desejos ou representações de representações). [...] Nós utilizaremos os termos de forma mais abrangente, tratando como informação não apenas fatos, mas também suposições dúbias ou falsas apresentadas como factuais".
} 
de seu próprio conhecimento, uma vez que interage na construção do contexto de comunicação em sala de aula.

\section{Comunicação e contexto na teoria da relevância de Sperber e Wilson}

Segundo Sperber e Wilson (1986/1995), todos estão constantemente engajados na tarefa de derivar (inferir) informação a partir do mundo físico em que estão inseridos e construir a melhor representação mental possível sobre ele. Mas, embora se compartilhe o mesmo ambiente físico, devido às peculiaridades que diferenciam as pessoas umas das outras, não se compartilha o mesmo ambiente cognitivo, isto é, as coisas não são percebidas por todos da mesma forma. Além de falarem línguas diferentes e de dominarem diferentes conceitos, as pessoas não constroem as mesmas representações mentais. Em outras palavras, ainda que os objetos do mundo físico estejam presentes (manifestáveis) a todos da mesma forma, as pessoas constroem representações mentais diferentes umas das outras.

Segundo essa abordagem sobre a comunicação humana, não se lida com o que se pode ver, mas sim com as habilidades cognitivas conceituais, com o conjunto de todos os fatos que se podem perceber ou inferir, o ambiente cognitivo de cada um. ${ }^{5}$ Não apenas os fatos sobre os quais se está consciente, mas também aqueles fatos no ambiente físico sobre os quais se é capaz de tomar consciência. Para que duas pessoas se comuniquem a respeito de algo, elas devem compartilhar um ambiente cognitivo.

Quando um comunicador deseja comunicar algo a seu ouvinte, ele, intencionalmente, chama a atenção de seu ouvinte tanto à informação que quer transmitir, quanto ao fato de querer transmiti-la. Por isso Sperber e Wilson consideram a comunicação um ato ostensivo, intencional, que se realiza por meio da derivação de inferências acerca das intenções do comunicador. Dois tipos de intenção estão envolvidos na comunicação, conforme descrito em (13):

(13) Intenções envolvidas no ato da comunicação, segundo Sperber e Wilson $(1995$, p. 58, 61)

i. Intenção informativa: tornar um conjunto de suposições $\{\mathrm{I}\}$ manifesto, ou mais manifesto, à audiência;

ii. Intenção comunicativa: tornar mutuamente manifesto, à audiência e ao comunicador, que o comunicador tem essa intenção informativa.

\footnotetext{
${ }^{5}$ Sperber e Wilson (1986/1995, p. 38).
} 
Pode-se considerar a intenção informativa como sendo uma camada de informação a ser apreendida e a intenção comunicativa, outra. No exemplo em (14), o ato ostensivo, por parte de um supervisor de parque, ao pronunciar seu enunciado, carrega uma intenção informativa e uma intenção comunicativa:

(14) Não é permitido trazer animais a este parque.

A intenção informativa do falante pode ser definida como sua intenção de informar seu interlocutor que naquele parque não se devem levar animais domésticos e que, caso ele tenha trazido algum, deve levá-lo embora. Que esta informação se torne manifesta - acessível no ambiente cognitivo do ouvinte - é a intenção informativa do falante. Sua intenção comunicativa é a de que tal informação seja mutuamente manifesta, isto é, torne-se comum ao ambiente cognitivo tanto do comunicador como do ouvinte.

Sendo a comunicação um ato ostensivo e intencional, o estímulo produzido para que se inicie a comunicação é aprioristicamente relevante, e disso Sperber e Wilson (1995, p. 158) depreendem a Suposição de Relevância Ótima e o Princípio de Relevância:

(15) Suposição de Relevância Ótima

a) $\mathrm{O}$ conjunto de suposições $\{\mathrm{I}\}$ que o comunicador pretende tornar manifesto ao ouvinte é relevante o suficiente para fazer valer a pena o ouvinte processar o estímulo ostensivo.

b) O estímulo ostensivo é o mais relevante que o comunicador poderia ter usado para comunicar $\{\mathrm{I}\}$.

(16) Princípio da Relevância

Todo ato de comunicação ostensiva comunica a presunção de sua relevância ótima.

Segundo Sperber e Wilson, a relevância de uma informação é individual, isto é, para um indivíduo uma informação pode ser relevante enquanto para outro, não. Um comunicador racional deve pretender que o estímulo que está usando pareça relevante o suficiente para atrair a atenção do ouvinte e o tornar disposto a investir o esforço necessário para a compreensão. A informação mais relevante é aquela que produz o maior número de efeitos contextuais e exige o mínimo de esforço de processamento. 
O contexto, segundo Sperber e Wilson (1995, p.134), “consiste não apenas das suposições expressas ou implicadas por enunciados precedentes, mas também das entradas enciclopédicas ligadas a qualquer conceito usado nessas suposições”. Trata-se, portanto, de um conceito cognitivo de contexto, pois as suposições são representações mentais dos indivíduos envolvidos no ato comunicativo. Pode-se dizer, conforme Santos (2005, p.205), que o contexto para Sperber e Wilson é "[...] uma construção psicológica que pode ser formada através do acesso a informações armazenadas na memória enciclopédica, através de informações retiradas do meio envolvente ${ }^{6}$ pelos sistemas sensoriais, ou através de representação da realidade implicadas pelo ato discursivo precedente". Todas essas fontes de informação estão presentes e atuantes durante o processo de ensino-aprendizagem e, portanto, fazem parte do contexto da situação em que esse processo se desenrola.

Segundo o princípio de relevância, a cognição humana tende a funcionar maximizando a relevância, e cada ato de comunicação ostensiva comunica uma presunção de relevância ótima. Em outras palavras, regularmente, as pessoas tentam encontrar o máximo de efeitos contextuais ao processarem informação e, ao realizar um ato de comunicação, o emissor do estímulo ostensivo sabe que o estímulo que ele escolheu é aquele que tem mais efeitos contextuais entre os que ele poderia ter escolhido.

Efeitos contextuais consistem na modificação e consequente aperfeiçoamento do contexto do enunciado, o que resulta no aperfeiçoamento da representação de mundo do ouvinte. A modificação do contexto, considerada um efeito contextual, é ocasionada pela interação entre informação nova e informação antiga e pode ser de três tipos: a informação nova combina-se com o contexto e produz implicações contextuais; a informação nova combina-se com o contexto e reforça suposições já existentes no mesmo; a informação nova combina-se com o contexto e contradiz suposições existentes, eliminando-as.

A partir do enunciado em (17) pode-se ilustrar cada um dos três tipos de efeitos contextuais acima descritos:

(17) Ninguém passou no exame de proficiência em língua estrangeira.

Esse enunciado (informação nova), ouvido por um aluno que, ao fazer a prova, tivera a sensação de não ter atingido a média (informação antiga, presente no contexto), origina um

\footnotetext{
${ }^{6} \mathrm{Ou}$ meio ambiente.
} 
efeito contextual na medida em que reforça a sensação de fracasso desse aluno. Considerando o mesmo indivíduo, o enunciado também origina outro efeito contextual, combinando-se com suposições antigas e produzindo implicações contextuais, mobilizando o indivíduo a estudar mais. No caso de algum aluno convicto quanto ao seu sucesso no exame, o enunciado em (17) produz efeito contextual porque contradiz a previsão de sucesso desse otimista, eliminando a suposição de que o exame fora fácil.

Conforme exemplificado e de acordo com a teoria da relevância, interação entre informação nova e contexto significa a informação nova produzir os efeitos contextuais descritos acima. Consequentemente, uma informação nova processada é irrelevante nos casos em que não se conecta de forma alguma a qualquer informação já no contexto, em que já existe uma suposição equivalente no contexto, porém mais forte, de maneira que a nova suposição não afeta a força daquela, sendo não informativa e irrelevante e em que a suposição contradiz outras suposições existentes no contexto, mas não é forte o suficiente para eliminá-las. ${ }^{7}$ Por isso, um professor, por exemplo, que tenha como objetivo criar situações em que o docente se envolva e tenha as melhores condições de aprendizagem, lidará com o contexto da situação de forma a causar o máximo de efeitos contextuais, para atingir o máximo de relevância possível.

Além de ser condição necessária para a relevância de um enunciado, os efeitos contextuais também são condição suficiente para essa relevância. Basta que o ouvinte os reconheça para alcançar a relevância do enunciado. Mas, paralelamente à intuição quanto à capacidade humana de distinguir informações relevantes de irrelevantes, as pessoas também têm intuições quanto ao grau de relevância dos enunciados. Observa-se que alguns enunciados têm mais efeitos contextuais do que outros, por isso a força de sua relevância parece ser maior no contexto por eles acessado do que os outros em seus contextos.

A força, além da quantidade de efeitos contextuais, é determinante do grau de relevância de um enunciado. Contudo, o esforço de processamento exigido ao acessar-se o contexto para a interpretação do enunciado também afeta a avaliação dos graus de relevância, pois efeitos contextuais são produzidos por meio de processos mentais e estes, como todos os processos biológicos, exigem algum esforço.

\footnotetext{
${ }^{7}$ Sperber e Wilson (1995, p.121) dizem, no entanto, que, mesmo nos casos em que a suposição propriamente dita é irrelevante, a escolha que o falante fez de utilizar uma suposição irrelevante pode ser relevante.
} 
Para explicar a participação do efeito e do esforço na avaliação da relevância, os autores baseiam-se na definição a seguir, em que Sperber e Wilson (1995, p.125) adotam o formato de definição com condições de extensão:

\section{(18) Relevância}

Condição de extensão 1: uma suposição é relevante num contexto à medida que seus efeitos contextuais neste contexto sejam grandes.

Condição de extensão 2: uma suposição é relevante num contexto à medida que o esforço exigido para processá-la neste contexto seja pequeno.

Implícitas estão, nessa definição, as condições suficiente e necessária para a relevância, além do que a avaliação da relevância de um enunciado passa a ser uma questão de equilíbrio entre output e input, ou seja, entre efeitos contextuais e esforço de processamento. ${ }^{8}$

Sperber e Wilson não pretendem definir o termo relevância semanticamente, mas sim explicar o conceito teórico de relevância como propriedade de processos mentais na psicologia cognitiva. Para serem relevantes, conforme foi demonstrado anteriormente, as suposições de um enunciado devem interagir com o seu contexto, isto é, deve, necessariamente, haver uma interação entre informação nova e informação antiga.

Com a finalidade de evidenciar a inconsistência da noção de que deve haver conhecimento mútuo entre falante e ouvinte para haver comunicação, os autores propõem a manifestabilidade (ou virtualidade) mútua e o ambiente cognitivo mútuo, enfatizando a atividade de cada um, a noção dinâmica da comunicação. Na abordagem da relevância, admite-se o não conhecimento mútuo das coisas, mas a possibilidade, ou virtualidade de se vir a percebê-las mutuamente, o que Grice não chegou a reconhecer. As proposições são mutuamente manifestáveis. Pode não haver nenhum tipo de registro mental quanto a um conceito comunicado pelo locutor, mas seu interlocutor, ao decodificar a mensagem, tem condições de acessar esse conceito. Pode não funcionar, mas existe a possibilidade para que isso aconteça. Em outras palavras, enquanto o conhecimento mútuo

\footnotetext{
${ }^{8}$ Poder-se-ia perguntar: como tratar, então, duas suposições entre as quais uma tem maiores efeitos contextuais do que a outra, logo aquela exige mais esforço de processamento para se acessarem tais implicações? Sperber e Wilson (1995, p. 126-127) admitem que o esforço para se computar uma implicação é proporcional aos efeitos por ele implementados, por isso pode ser ignorado. Em outras palavras, o esforço de processamento necessário para computar uma implicação contextual ou elevar ou baixar a força de uma suposição não é suficiente para anular a contribuição feita pela implicação à relevância.
} 
explica somente a comunicação que dá certo, a manifestabilidade mútua explica, também, casos em que não funciona.

Paralelamente, com relação ao contexto de ensino-aprendizagem, o professor que conduz a situação com vistas ao atingimento do maior número de efeitos contextuais possível por parte dos estudantes jamais terá garantias quanto aos efeitos realmente atingidos por eles, uma vez que, embora haja uma intersecção entre os ambientes cognitivos dos participantes, devido à manifestabilidade mútua, as suposições armazenadas de um diferem das dos outros e a nova informação terá influências diferentes quando combinadas com o conhecimento enciclopédico armazenado na mente de cada um. Dessa forma, o aluno oriundo de uma classe social desprivilegiada, onde se fala uma variedade não culta do português, fará associações e inferências diferentes das que fará o aluno que vive entre pessoas que falam a variedade culta de sua língua. Uma noção de contexto griceana não tem como tratar de casos assim, uma vez que funciona com base em conhecimento mútuo pressuposto, sem considerar as individualidades cognitivas de cada aluno.

Ao interpretar o enunciado, logo, ao tentar ir ao encontro da intenção comunicativa do falante, o ouvinte entra num processo de interpretação que envolve acesso a conceitos e entradas enciclopédicas (formação de hipóteses) e dedução (confirmação ou rejeição de hipóteses). Assim, a interpretação de um enunciado será o processamento de informações novas combinadas a informações antigas. As informações antigas estão na memória em forma de conceitos aos quais ligam-se informações enciclopédicas. As informações nos conceitos e na enciclopédia formam o contexto no qual o enunciado é processado. Portanto, durante o processamento de um enunciado, o contexto vai se formando, a partir de um contexto inicial, e se modificando com o reforço de suposições e com o aparecimento de novas suposições contextuais, que são as implicaturas (suposições e conclusões implicadas).

A partir da comparação feita até agora entre as teorias de Grice e de Sperber \& Wilson, no que tange à noção de contexto de comunicação, prossegue-se dentro do objetivo deste texto, de demonstrar as vantagens de se adotar a noção cognitiva de contexto, oriunda da teoria da relevância, como sendo o contexto em situações de ensino-aprendizagem de língua portuguesa. ${ }^{9}$

\footnotetext{
9 A proposta aqui expressa é semelhante à abordagem de métodos comunicativos para o ensino de língua estrangeira e materna. Está-se, aqui, corroborando tais métodos à luz da teoria da relevância, por considerar-se essa teoria cognitiva muito elucidativa e apropriada como base teórica de tais abordagens.
} 


\section{Relevância e contexto no ensino-aprendizagem de língua portuguesa}

Grice não chegou a considerar a dinâmica descrita acima, que se opera na cognição dos indivíduos, por isso não lidou com essa noção de contexto, atendo-se ao fato de que, por termos condições de inferir as intenções do outro, compreendemos o que ele quer dizer, mesmo que isso vá muito além do dito. Fato novo no estágio em que se encontravam os estudos e, por isso, revolucionário, mas ainda totalmente voltado para a filosofia e para o que é geral no ser humano, não levando em conta sua mente e o processamento de informação como processo mental e individual.

Wolf (1999), que também se interessou pelo contexto durante o ensino-aprendizagem de línguas, ao falar em contexto, refere-se ao contexto comunicativo da teoria da relevância, de Sperber e Wilson (1986/1995), conforme já apontado anteriormente: um conjunto de suposições que os indivíduos resgatam de sua memória enciclopédica, que se forma no decorrer da conversação e que se modifica ao longo do ato comunicativo, de acordo com os propósitos dos participantes. ${ }^{10}$

Como foi visto nas seções anteriores, os autores mostram que a comunicação se dá através da conexão entre a informação já presente no contexto e a nova informação recebida, o que leva a efeitos contextuais, isto é, modificações no ambiente cognitivo do ouvinte, fortalecendo certas informações já existentes, rejeitando outras e originando, ou implicando, novas suposições.

Numa situação que vise promoção do processo de ensino-aprendizagem (em sala de aula, ou não), quanto mais se leva o aprendiz a estabelecer associações entre seu contexto cognitivo e as novas informações, mais efeitos contextuais se originam, o que significa mais esforço de processamento cognitivo, nos termos de Sperber e Wilson, e, consequentemente, mais significado relevante para quem aprende.

Wolf sugere a utilização do princípio de relevância no preparo de contextos para o ensino de segunda língua, o que pode ser estendido ao ensino de língua portuguesa e para o ensino em geral, pois, conforme Pozo (1998) e Jackendoff (1985), a construção de conhecimento baseia-se no estabelecimento de associações entre as categorias conceituais que

\footnotetext{
${ }^{10}$ No Brasil, pesquisadores de Santa Catarina, como Fábio José Rauen (2005, 2010), já apontaram a evolução que a teoria da relevância de Sperber e Wilson representa nos estudos da comunicação humana e sua repercussão no ensino de língua portuguesa.
} 
já se possuem e a realidade, isto é, a nova informação. Portanto, conforme tal sugestão de Wolf, que vai ao encontro das posições adotadas na presente pesquisa, a noção de contexto de Grice não é suficiente para explicar o contexto em situações de ensino-aprendizagem. Grice, diferentemente de Sperber \& Wilson, não chegou a tratar das categorias conceituais, nem de dados da realidade, lidando com a realidade suposta apenas, com exemplos pré-construídos que simulam a realidade, sem considerar a conversação autêntica e as características individuais dos falantes/ouvintes.

Tendo adotado a noção cognitiva de contexto, com base na teoria da relevância, discutirse-á, deste ponto em diante, sobre a necessidade de que o contexto em situações de ensinoaprendizagem seja dinâmico e de que os efeitos contextuais sejam o mais numerosos possível. Partindo de autores que criticam a forma como a língua é ensinada, tentar-se-á mostrar que a adoção dessa noção de contexto tornaria o ensino-aprendizagem de língua portuguesa mais eficaz, por atingir mais relevância na cognição dos estudantes.

Para que se atinja relevância ótima no contexto de ensino-aprendizagem, é necessário que este contexto não seja dado de antemão, mas sim construído ao longo do processo. ${ }^{11}$ No entanto, o contexto de ensino, conforme conclusões de linguistas a seguir, frequentemente, é um contexto dado, tanto linguística quanto não linguisticamente. Conforme registra Neder (1992, p.56), a gramática é dada "para se cumprir um programa previamente estabelecido sem se levar em conta as dificuldades ou não dos alunos no emprego que fazem efetivamente da linguagem, nessa ou naquela ocasião, num processo de interação verbal". Numa situação dessas, a relevância do contexto de ensino-aprendizagem é completamente posta de lado, uma vez que nem as dificuldades dos alunos são consideradas. Vê-se, aqui, a utilização de um contexto dado e a total ausência da participação dos alunos no seu desenrolar.

Sobre o mesmo tema, o ensino da gramática da língua portuguesa, Neves (1990, p.1828) também registra como é ensinada a gramática, dizendo que mais de $50 \%$ dos professores declara que parte de textos (muitas vezes dos próprios alunos) para a exercitação gramatical, cerca de $40 \%$ declara partir da teoria e cerca de 5\% declara privilegiar a exercitação como ponto de partida das lições. Em sua pesquisa, a autora verificou que partir do texto significa retirar

\footnotetext{
11 Nesse sentido, a teoria de Grice não é apropriada para se explicar o contexto comunicativo do ensinoaprendizagem. Em sua teoria, o conhecimento mútuo desempenha papel fundamental, levando a uma compreensão do contexto enquanto conjunto de informações dadas de antemão, consideradas sabidas pelos participantes do ato comunicativo.
} 
de textos unidades (frases ou exemplos) para análise e catalogação. No item sobre como se ensina, tem papel relevante o livro didático, que, infelizmente, aparece como a única fonte de consulta e informação da grande maioria dos professores no que diz respeito a fatos da língua.

Os fatos trazidos por Neves (1990) também revelam a não participação dos alunos na construção das atividades propostas para a sua aprendizagem. Embora partindo de textos escritos pelos alunos, a condução das aulas não busca um contexto com relevância ótima para eles, porque desses textos são retiradas frases que servem como exemplo de análise, ao invés de serem utilizados como ponto de partida para discussões em torno do tema e da relação do aluno com sua língua, possibilitando, assim, a verdadeira participação do aluno na comunicação em sala de aula e, consequentemente, originando o máximo de efeitos contextuais pelo esforço de processamento exigido.

Num artigo intitulado Reflexões sobre o ensino/aprendizagem de gramática, Zuleika Murrie (2001, p.66-67) destaca fatos reveladores sobre o tema:

Ao se considerar o conceito de gramática como um conjunto de regras significativas de uma língua, conhecido e dominado pelos falantes nativos em uma comunidade, elaborado e aceito socialmente como próprio à comunicação, através da linguagem verbal, formula-se a seguinte questão: que gramática ensinar àqueles que já a conhecem?As crianças conseguem derivar oralmente regularidades presentes no sistema gramatical, sem nunca terem sido expostas a elas. É o caso de emissões do tipo: "eu ponhei", "eu fazi” onde o paradigma dos verbos regulares se sobrepõe aos irregulares, mesmo sem que tal emissão tivesse sido falada pelos adultos com quem convivem. $\mathrm{O}$ conhecimento da gramática de uma língua faz parte integrante do conhecimento linguístico do usuário. $\mathrm{O}$ falante é capaz de operacionalizar as regras, sem nem mesmo conhecê-las, denominá-las ou pensar sobre elas (por exemplo, a emissão "por favor feche a porta" jamais será falada pelo nativo da seguinte forma "favor por porta a feche"). O ensino de gramática, sob este ponto de vista, deixa de ser apenas um conjunto de regras prescritivas ou normativas, para transformar-se em uma explicitação das regras de uso da língua, em situações significativas. [...] A gramática entendida como uma construção interativa em processo, através do tempo e espaço, introduz no conceito um aspecto histórico e dialético e sugere algumas reflexões: qual a gramática ensinada pela escola? Por que ensinar gramática? Que gramática deve o aluno dominar?

A ideia-chave a ser ressaltada no texto da autora acima está na pergunta inicial "que gramática ensinar àqueles que já a conhecem?”. A prática de ensinar ao aluno o que ele já sabe revela, quanto à noção de contexto da comunicação relevante, o equívoco de, ao invés de acessarem e criarem um contexto à medida que vão avançando, tanto professores como alunos 
primeiro decifrarem um contexto para então avançarem na construção do saber. Como resultado, muito do que ocorre na sala de aula mais se parece com um jogo de adivinhação ou de repetição do que com comunicação genuína.

Mas não é esse o sentido dado por Murrie a já sabem. Isso significa, sim, a capacidade inata do indivíduo de adquirir a gramática de sua língua à medida que avança em idade, naturalmente, de maneira que, ao iniciar o período escolar, toda criança traz consigo um complexo conhecimento a respeito de sua língua, embora não de forma consciente. Esse conhecimento permite que a criança comunique-se em todas as situações que deseja se comunicar e compreenda frases nunca antes ouvidas, uma vez que já tem internalizadas as regras da gramática de sua língua.

Considerando-se esse sentido da frase já sabem, a maneira apropriada para ensinar a gramática envolve um contexto comunicativo que inclua a gramática que o aluno já conhece e que evolua com o acréscimo de suposições e informações que atinjam relevância nesse contexto, pois, ao combinarem-se com ele, geram efeitos contextuais. Como a própria autora destaca na citação acima, o ensino da gramática passa a ser uma "explicitação das regras de uso da língua, em situações significativas". Para uma situação ser significativa, ela deve levar em conta o ambiente cognitivo dos alunos e propor novas situações que formem um contexto capaz de originar efeitos contextuais, atingindo relevância ótima em contato com esse ambiente.

Britto (2009, p. 100), a propósito da aprendizagem da escrita, diz que "[...] o aprendizado efetivo da escrita não decorre de um processo de treinamento, mas da inserção do sujeito no mundo, da relação que estabelece entre o que aprende e seu universo sociohistórico." Para que o universo sociohistórico do aluno seja considerado, não é possível que o contexto comunicativo em sala de aula, ou em outro ambiente de ensino-aprendizagem, seja dado de antemão, sem a participação do professor e do aluno em sua construção.

Suassuna (2003, p.122) refere o fato de a escola não privilegiar a construção do saber, mas sempre o considerar um produto acabado a ser reproduzido como responsável por matar "pela raiz as possibilidades históricas de intervenção no real a partir da sua interpretação pelo saber. Porque as coisas não são vistas em sua relação. Porque ninguém se atreve a criar modos de entender o mundo para agir sobre ele."

Considerando as conclusões desses pesquisadores e relacionando-as à noção de contexto de ensino e aprendizado de língua portuguesa, pode-se ver que, em grande parte, a focalização é feita sobre a dimensão informativa do conteúdo estudado e dos textos lidos, determinando-se, 
assim, o contexto a partir do qual o aluno aprenderá. Para se determinar o contexto, é necessário privar-se o aprendiz de formular seu próprio conjunto de suposições. Como se poderia evitar tudo isso? O material poderia ser elaborado seguindo uma apresentação que não seja sempre linear e sequencial. Em outras palavras, deveria haver a oportunidade tanto para o aluno, quanto para o professor de interagir com o contexto, de tal maneira que as suposições relevantes pudessem ser fornecidas pelo próprio aluno no decorrer das atividades (interpretação de textos, descrição das regras da gramática da língua, execução de projetos de pesquisa e outras).

De acordo com as noções de relevância vistas aqui, propõe-se que se aumente o ganho cognitivo do aluno, pelo menor esforço possível de processamento. Significa dar ao aprendiz acesso a um número maior de efeitos contextuais. Mas, quando o material usado requer muito pouco esforço de processamento, pois o contexto não possibilita efeitos contextuais que o enriqueçam e modifiquem, esse material torna-se irrelevante, portanto, não merecedor de esforço para seu processamento.

Wolf oferece algumas sugestões para a abordagem textual (uma das atividades realizadas em sala de aula) que encorajem a exploração do contexto, as quais são resumidamente apresentadas em (19):

(19) Sugestões de Wolf (1999, p. 95-109) para a exploração do contexto em situações de ensino-aprendizagem

i. variar o meio, por exemplo, projetando uma capa de livro, dramatizando uma passagem etc.;

ii. variar o ponto de vista, tal como reescrever a história sob um outro ponto de vista, tal como o ponto de vista de um dos personagens;

iii. variar o marco temporal do texto em que os alunos reescrevem uma história, começando em um ponto diferente no tempo.

Pode-se perguntar de que forma essas sugestões vão ao encontro da noção de contexto e efeitos contextuais de Sperber e Wilson, descritas nas seções anteriores. A primeira sugestão, (19i), é a de variar o meio em que se apresenta um conteúdo para o aluno estudar ou desenvolver. Ao invés de, por exemplo, simplesmente falar de uma obra literária a ser lida, interpretada, ou resumida, pode-se apresentá-la mediante a projeção da capa do livro numa tela, ou a dramatização de uma de suas passagens.

Essas duas alternativas tornam manifestas inúmeras suposições, presentes no ambiente cognitivo do aluno, possibilitando que se originem efeitos contextuais a partir da interação entre a informação inicial e as suposições armazenadas. Tanto a projeção da capa, quanto a 
dramatização levam a memória enciclopédica a tornar manifestas informações sobre imagens, sons, movimentos do corpo, isto é, linguagens diferentes da linguagem verbal. Com isso, o aluno fará um esforço muito maior para encontrar a relevância do ato ostensivo realizado pelo professor para iniciar a comunicação, mas, por outro lado, também encontrará muito mais efeitos contextuais, participando, então, da construção do contexto da comunicação e envolvendo-se intensamente com a atividade proposta. O maior esforço é compensado pelo ganho em efeitos contextuais.

A segunda sugestão de Wolf, (19ii), diz respeito ao ponto de vista sob o qual o aluno deve reescrever uma história que foi lida anteriormente, como exercício de produção textual. Fazendo isso, o aluno estará se colocando no lugar de um dos personagens, o qual recontaria a história sob o seu ponto de vista. Essa prática movimenta a memória enciclopédica do aluno, no que tange ao seu conhecimento a respeito do que o personagem escolhido pensa, como ele age na história, qual o seu destino e tudo o que se relaciona a ele. Todas essas informações tornar-se-ão mutuamente manifestas, pois terão relevância no contexto que começa a se formar a fim de que a atividade seja executada.

A terceira sugestão de Wolf, (19iii), variar o marco temporal do texto em que os alunos reescrevem uma história, começando em um ponto diferente no tempo, novamente, propõe um contexto que não é óbvio ao aluno, levando-o a mais esforço de processamento e, consequentemente, mais efeitos contextuais, isto é, mais relevância. Ao alterar o marco temporal da história, o aluno terá de tornar manifestas várias suposições que não estavam manifestas quando ela foi contada de forma linear, exigindo esforço extra e, portanto, efeitos contextuais diferentes também. Ele terá de acessar seu conhecimento enciclopédico sobre os personagens e acontecimentos, com vistas a direcionar a mesma história através de um outro caminho, considerando outros pontos de referência quanto ao tempo. Isso exigirá alterações em seu ambiente cognitivo, e, consequentemente, produção de efeitos contextuais, compensando todo o esforço cognitivo realizado.

Os exemplos de Wolf descritos e analisados acima demonstram a importância do conceito de contexto cognitivo oriundo da teoria da relevância para o ensino-aprendizagem de línguas e, portanto, de língua portuguesa. Neles focaliza-se o contexto que vai se formando e transformando no decorrer da comunicação que se dá entre professor e aluno e, paralelamente, entre outras fontes de informação e o aluno, uma vez que o professor é uma delas, que indica outras. Esse contexto é explicado mediante uma teoria cognitiva, como a da relevância, mas 
não o é por uma teoria que considera o conhecimento mútuo como sendo pressuposto, como a teoria de Grice.

\section{Considerações finais}

Espera-se que este texto tenha contribuído para reforçar a importância do tipo de comunicação realizado entre quem ensina e quem aprende língua portuguesa. Concorda-se com Santos (2005, p. 205), quando afirma: “A acessibilidade do contexto do conteúdo da comunicação a ambos os interlocutores, emissor e receptor, é outra condição para o sucesso da comunicação." A primeira condição a que se referiu para o sucesso da comunicação é a inferência que o ouvinte faz do conteúdo significativo pretendido pelo comunicador.

Tentou-se mostrar, aqui, a importância da noção de contexto de Grice (1989), em sua teoria das implicaturas conversacionais, na década de 60, com relação ao modelo de código da comunicação, em que as intenções dos participantes não desempenhavam papel algum na transmissão e recepção de mensagens e, consequentemente, na compreensão das mesmas. Grice, já em 1948, ao descrever o significado não natural, destacou a importância das intenções de falantes e ouvintes, ao conversarem e compreenderem-se. Mas a sua teoria ficou muito apoiada no conhecimento mútuo que deve haver entre os participantes do ato de comunicação, deixando de considerar o conhecimento enciclopédico armazenado na memória e todas as suposições manifestáveis no ambiente físico, além das suposições implicadas pelos enunciados precedentes no discurso, os quais interferem na compreensão durante o ato comunicativo e participam da construção e modificação constante de seu contexto.

Na sequência, apresentou-se a teoria da relevância, de Sperber e Wilson (1986/1995), como alternativa adequada no que tange ao contexto de comunicação entre os indivíduos, de maneira geral, com vistas a indicá-la como a noção apropriada de contexto de comunicação em situações de ensino-aprendizagem de língua portuguesa. Sperber e Wilson introduzem no tratamento da comunicação conceitos como ambiente cognitivo, informações enciclopédicas, manifestabilidade mútua de suposições e informações, considerando o contexto como uma construção na qual entram a memória enciclopédica dos indivíduos participantes, o meio ambiente em que se encontram, além de implicações contextuais dos enunciados já processados no discurso.

Compreende-se que este seja o contexto a ser considerado e buscado em situações que visem ao aprendizado de língua portuguesa. Um contexto desses, em sua definição, inclui a 
noção de construção, na qual participam o professor e o aluno. Ao construir o contexto em sala de aula, o aluno participa ativamente da construção de seu conhecimento, o qual se dá mediante o máximo possível de ganho cognitivo em termos de efeitos contextuais, pelo esforço cognitivo despendido no processamento das informações.

Cabe, portanto, aos professores de língua portuguesa planejarem as situações de ensino e aprendizagem de modo que os alunos participem da construção do contexto. Esta é a melhor forma de fazer com que as aulas produzam uma diferença positiva em seus ambientes cognitivos.

\section{Referências Bibliográficas}

BRITTO, L. P. L. A sombra do caos. Ensino de língua X tradição gramatical. São Paulo: Mercado das Letras, 2008. 288p.

CARSTON, R. Implicature, explicature and truth-theoretic semantics. In: KEMPSON, R., Mental representations: the interface between language and reality. Cambridge: Cambridge University Press, 1988. p.155-181

GRICE, P. Meaning. In: GRICE, P. Studies in the way of words. Cambridge, Mass.: Harvard University Press, 1989. p.22-40.

GRICE, P. Logic and conversation. In: GRICE, P. Studies in the way of words. Cambridge, Mass.: Harvard University Press, 1989. p.213-223.

JACKENDOFF, R. Semantics and cognition. Cambridge, Mass.: The MIT Press, 1985. 304p.

LEVINSON, Stephen C. Pragmatics. Cambridge: Cambridge University Press, 1983. 420p.

MURRIE, Z. F. (org.) O ensino de português. São Paulo: Contexto, 2001. 176p.

NEDER, M. L. C. Ensino de linguagem: a configuração de um drama. Dissertação de mestrado, Universidade Federal de Mato Grosso, 1992.

NEVES, M.H.M. Gramática na escola. São Paulo: Contexto, 1990. 72p.

POZO. J. Teorias cognitivas da aprendizagem. Porto Alegre: Artes Médicas, 1998. 284p.

RAUEN, F. J. Contribuições da teoria da relevância aos estudos da pragmática, da cognição e da textualidade: questões e propostas de trabalho. In: ENCONTRO DO CÍRCULO DE ESTUDOS LINGUÍSTICOS DO SUL, 5. 2003, Curitiba. Anais..., Curitiba: UFPR, 2003, p. 543-548.

Interação discente/docente em espaço virtual de aprendizagem: análise com base na teoria da relevância. Cadernos de Letras da UFF, v. 41, p. 231-250, 2010. 
SANTOS, J. A. Cognição e comunicação no âmbito da pedagogia: uma reflexão à luz da teoria da relevância. Revista Encontros Científicos, 1, p.204-208.

SMITH, N.; WILSON, D. Introduction. Lingua, v. 87, p.1-10, 1992. crossref http://dx.doi.org/10.1016/0024-3841(92)90022-B

SPERBER, D. e WILSON, D. Relevance: communication and cognition. Oxford: Blackwell, 1986/1995. 326p.

SUASSUNA, L. Ensino de língua portuguesa: uma abordagem pragmática. 6 ed. Campinas: Papirus, 2003. 242p.

WILSON, D.; SPERBER, D. Inference and implicature. In: DAVIS, S. Pragmatics: a reader. Oxford: Oxford University Press, 1991. p. 377-396.

WOLF, A. J. E. Context and relevance theory in language teaching: an exploratory approach. IRAL (International Review of Applied Linguistics in Language Teaching), v.XXXVII/2, p. 95-109, 1999. crossref http://dx.doi.org/10.1515/iral.1999.37.2.95 